\title{
Is the United States Really Losing the International Horse Race in Academic Achievement?
}

\author{
Erling E. Boe \\ University of Pennsy/vania, boe@gse.upenn.edu \\ Sujie Shin \\ University of Pennsylvania
}

Follow this and additional works at: https://repository.upenn.edu/gse_pubs

Part of the Education Commons

\section{Recommended Citation}

Boe, E. E., \& Shin, S. (2005). Is the United States Really Losing the International Horse Race in Academic Achievement?. Retrieved from https://repository.upenn.edu/gse_pubs/5

Copyright Phi Delta Kappa International. Reprinted from Phi Delta Kappan, Volume 86, Issue 9, May 2005, pages 688-695.

This material is posted here with permission of Phi Delta Kappa. Content may not be copied or emailed to multiple sites or posted to a listserv or website without the copyright holder's express written permission. However, users may print, download, or email articles for individual use.

This paper is posted at ScholarlyCommons. https://repository.upenn.edu/gse_pubs/5

For more information, please contact repository@pobox.upenn.edu. 


\title{
Is the United States Really Losing the International Horse Race in Academic Achievement?
}

\author{
Abstract \\ The results of international assessments of student achievement are far more nuanced than the \\ headlines lead us to believe. Having examined six comparisons of performance - in various subjects and \\ at various levels - by students in the U.S. and other industrialized nations, Mr. Boe and Ms. Shin conclude \\ that the dire pronouncements about America's standing are greatly exaggerated. \\ Disciplines \\ Education

\section{Comments} \\ Copyright Phi Delta Kappa International. Reprinted from Phi Delta Kappan, Volume 86, Issue 9, May 2005, \\ pages 688-695. \\ This material is posted here with permission of Phi Delta Kappa. Content may not be copied or emailed to \\ multiple sites or posted to a listserv or website without the copyright holder's express written permission. \\ However, users may print, download, or email articles for individual use.
}




\section{$\begin{array}{lllllllllllllllllll}E & X & A & M & I & N & I & N & G & T & E & S & T & S & C & 0 & R & E & S\end{array}$}

\section{Is the United States Really Losing the International Horse Race in Academic Achievement?}

The results of international assessments of student achievement are far more nuanced than the headlines lead us to believe. Having examined six comparisons of performance - in various subjects and at various levels - by students in the U.S. and other industrialized nations, Mr. Boe and Ms. Shin conclude that the dire pronouncements about America's standing are greatly exaggerated.

\section{BY ERLING E. BOE AND SUJIE SHIN}

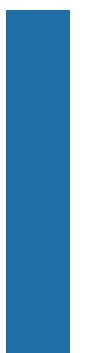

T IS widely believed and lamented that U.S. students perform poorly on international comparisons of academic achievement. For example, Edward Silver reports that U.S. seventh- and eighth-grade students performed poorly on the mathematics section of the Third International Mathematics and Science Study (TIMSS 1995) and that this indicates "a pervasive and intolerable mediocrity in mathematics teaching."1 Likewise, the Institute of Education Sciences (IES) in the U.S. Department of Education attributed the reportedly poor performance of U.S. middle-grade students on the TIMSS 1995 mathematics assessment to the ineffectiveness of mathematics education. ${ }^{2}$ Such perceptions have led to grave concerns about the future economic competitiveness of the U.S. For example, Rita Colwell, the former director of the National Science Foundation, has stated that if the U.S. is to maintain its position in the world economy, it is critical for the nation's students to achieve at high levels in mathematics and science. ${ }^{3}$

ERLING E. BOE is a professor in the Graduate School of Education and a co-director of the Center for Research and Evaluation in Social Policy, University of Pennsylvania, Philadelphia, where SUJIE SHIN is a research assistant. 
Given the concern about the strength of the U.S. economy, it is often said that the nation's students perform poorly compared with students in "many" other industrialized nations. This indeed is true. One can pick a particular survey (e.g., TIMSS 1995), subject matter (e.g., mathematics), and grade level (e.g., grade 8) and find "many" industrialized nations that scored significantly higher than the U.S. (e.g., France, Japan, and Switzerland). ${ }^{4}$ Yet it is also true that U.S. students perform better than students in many industrialized nations. For example, the U.S. scored significantly higher than many industrialized nations (e.g., France, Germany, and Switzerland) in the 1991 Reading Literacy Study at grade $4 . .^{5}$ (Throughout this article, "significantly" refers to statistical significance.)

Thus, depending on one's interest or agenda, a particular survey result can be selected to support almost any conclusion about how the U.S. stands in the international achievement horse race. For instance, in order to support the conclusion that the U.S. was at risk of falling well behind other nations in economic competitiveness, the first item of evidence cited in A Nation at Risk was "that on 19 academic tests American students were never first or second and, in comparison with other industrialized nations, were last seven times. ${ }^{6}$ No mention was made of which international tests, grade levels, or subjects were selected for these comparisons, and nothing was said about how U.S. achievement on average compared with that of other industrialized nations. ${ }^{\text {? }}$

A much more objective and accurate assessment of the standing of the U.S. in international comparisons would be based on the results of multiple surveys, multiple subject matters, and multiple grade levels. Fortunately, another generation of international achievement surveys has been completed since 1990, and it is worth looking at the U.S. performance on these more recent assessments. In addition to being of high technical quality, these international assessments are not limited to mathematics and science, as were surveys from previous years, but also include subjects such as reading and civics.

The perception of poor performance by U.S. students on international comparisons is typically attributed to the ineffectiveness of American public education. Educators and policy makers of widely different perspectives embrace this conclusion because it creates enormous pressure for change. It is useful to those who are dedicated to reforming public education in various ways, as well as to those who seek to diminish public schooling through strategies such as voucher programs that would increasingly privatize the system. With so much at stake, it is important to know just how well U.S. students have performed on recent international assessments of achievement. Therefore, we have assembled and organized the results of all major international achievement surveys conducted from 1991 through 2001 (2003 results were published subsequently) in order to determine how well U.S. students have performed compared with their peers from other industrialized nations. More particularly, we have sought to address the following questions:

- How do U.S. achievement scores overall compare with scores from other industrialized nations?

- How does U.S. achievement by subject matter compare with that of other industrialized nations?

- How does U.S. achievement by grade level compare with that of other industrialized nations?

- How does U.S. achievement compare with that of its major economic competitors - the other G7 nations (Canada, France, Germany, Italy, Japan, and the United Kingdom)?

- How does the achievement of U.S. students from various racial and ethnic groups compare with that of other G7 nations?

\section{BRINGING IT ALL TOGETHER}

The first step in our analysis was to assemble the achievement results for reading, mathematics, science, and civics of all international surveys conducted from 1991 through 2001 under the auspices of either the International Association for the Evaluation of Educational Achievement (IEA) or the Organisation for Economic Co-operation and Development (OECD). ${ }^{8}$ National mean achievement scores for 22 industrialized nations that participated in two or more of the six surveys analyzed were obtained from primary sources for each of the surveys. ${ }^{9}$ These sources also provided information on the statistical significance of the difference between the mean achievement scores of the U.S. and the mean achievement scores for each industrialized nation participating in a given survey.

Achievement results from the six surveys were aggregated as appropriate to address the research questions. ${ }^{10}$ Cross-national comparisons were based on national comprehensive scores (e.g., full scale scores in mathematics) rather than on subscale scores (e.g., score in algebra).

\section{U.S. ACHIEVEMENT BY SUBJECT MATTER}

The perception that the U.S. performs poorly on international assessments of achievement is typically associated with mathematics. This perception may not be accurate, and it ignores U.S. performance in other subjects.

Figure 1 presents U.S. achievement compared with that of other industrialized nations in four subjects aggregated 
across six surveys and the fourth, eighth, ninth, and 10th grades. In mathematics, less than half the nations (44\%) scored significantly above the U.S., while $37 \%$ of the nations had scores equal to those of U.S. The remaining $19 \%$ scored significantly below the U.S. Viewed this way, the aggregated results make it clear that the U.S. did not perform "poorly." Instead, the U.S. mathematics score was somewhat below average. To say that the U.S. performed poorly, one would expect at least $75 \%$ of industrialized nations to have scored significantly higher. Nonetheless, efforts to improve mathematics instruction and learning must continue, and perhaps be intensified, because only $26 \%$ of U.S. students performed at the proficient level or above in mathematics on the 2000 National Assessment of Educational Progress (NAEP). ${ }^{11}$

In contrast with mathematics, the U.S. was much more competitive with other industrialized nations in three other subjects. The U.S. performed at a high level in civics (no nation scored significantly higher) and in reading (only $13 \%$ of nations scored significantly higher). In science the U.S. performed about average (with $25 \%$ of nations scoring significantly higher and $31 \%$ lower). A case can be made that learning each of the four subjects is a vital objective for public school students; certainly reading is as basic as mathematics. Yet scant praise is voiced for American public schools because their reading scores are highly competitive. Instead, U.S. public schools are castigated because their mathematics scores are generally below average internationally.

A more balanced perspective is that, overall, U.S. students score somewhat higher than their peers in other industrialized nations, with only $19 \%$ of other nations scoring significantly higher and 38\% significantly lower. Thus when all four subjects are weighted equally, U.S. students generally perform above average in international comparisons, not poorly. There are many good reasons for improving the effectiveness of U.S. public education, but not because students generally perform poorly in comparison with their peers from other industrialized nations.

\section{U.S. ACHIEVEMENT BY GRADE LEVEL}

Eric Hanushek, a researcher and often a critic of U.S. public education, observed that "in international comparisons, U.S. students start out doing well in elementary grades and then fade by the end of high school," at which point U.S. students outscore only Lithuania,
Cyprus, and South Africa. ${ }^{12}$ Hanushek based this observation on an analysis of TIMSS 1995 results in which he judged high school performance to be represented by the achievement of students at age 17 (i.e., grade 12). This interpretation is incorrect, however, because the TIMSS 1995 tests

\section{FIGURE 1.}

Relative Performance of U.S. and Other Industrialized Nations on International Comparisons, by Subject*

\section{Mathematics}

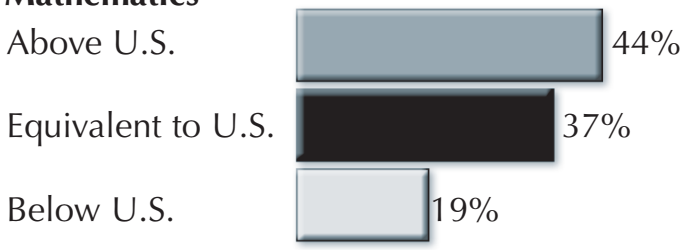

2. Civics

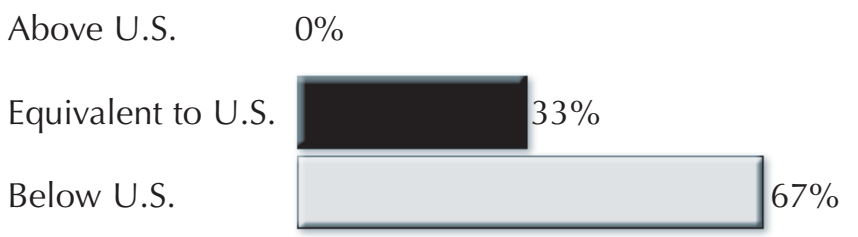

\section{Reading}

Above U.S.

Equivalent to U.S.

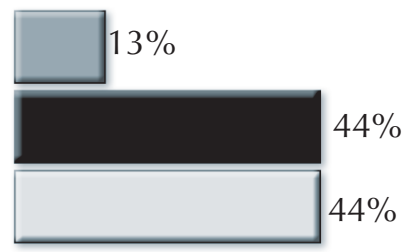

Below U.S.

\section{Science}

Above U.S.

Equivalent to U.S.

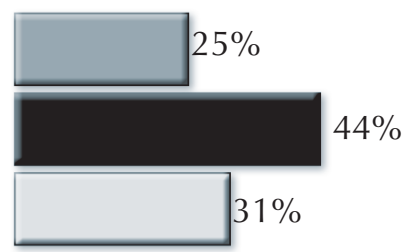

Below U.S.

\section{Median of Four Subjects}

Above U.S.

Equivalent to U.S.

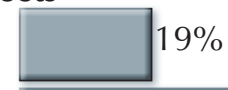

Below U.S.

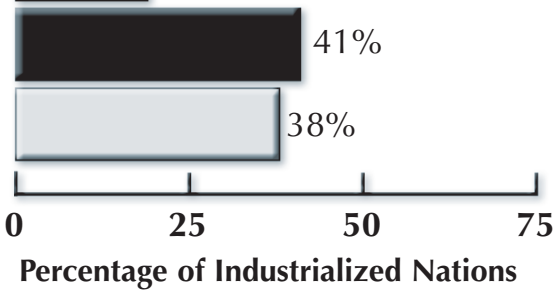

Sources: Five international education surveys sponsored by IEA and one by OECD.

* Results for each subject were aggregated across grades 4, 8, 9, and 10. 
were administered to students during the "final year of secondary school," as defined by each participating nation. As we have shown elsewhere, the number of years of schooling from grade 8 to the final year of secondary school varied widely across the 21 other nations in the relevant TIMSS 1995 sample (from about three years to almost eight years). ${ }^{13}$ When the gain or loss in national mean mathematics scores from grade 8 to the end of secondary school is plotted against the years of schooling past grade 8 , the result is a crossnational correlation of .71. Thus the number of years of schooling beyond grade 8 is a major determinant of how well a nation will perform by the end of secondary school. Since U.S. students are somewhat disadvantaged in this comparison, with only four years of schooling past grade 8, it is not appropriate to conclude from TIMSS 1995 data that the U.S. performed poorly in international comparisons at the secondary level.

\section{FIGURE 2.}

\section{Relative Performance of U.S. and Other Industrialized Nations on International Comparisons, by Grade Level*}

\section{Elementary (Grade 4)}

Above U.S.

Equivalent to U.S.

Below U.S.

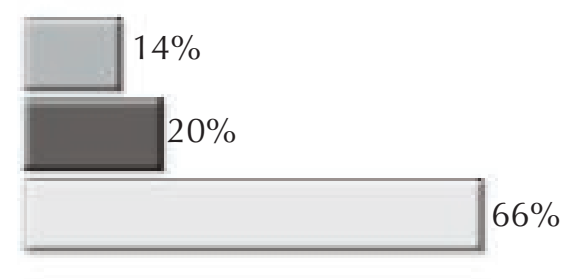

\section{Middle (Grades 8, 9)}

Above U.S.

Equivalent to U.S.

Below U.S.

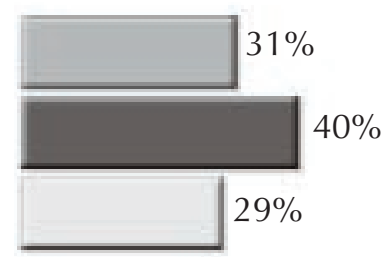

\section{Secondary (Grade 10)}

Above U.S.

Equivalent to U.S.

Below U.S.

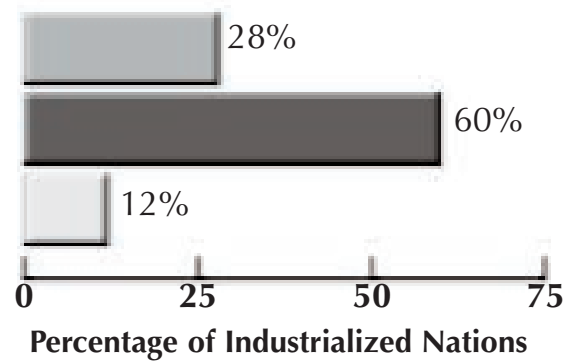

Sources: Five international education surveys sponsored by IEA and one by OECD.

* Results for each grade level were aggregated across reading, mathematics, science, and civics.
Fortunately, the Programme for International Student Assessment (PISA 2000) provides achievement scores in reading, mathematics, and science for students at grade 10 (i.e., age 15) from 21 industrialized nations. ${ }^{14}$ Therefore, the best understanding of grade-level trends in U.S. achievement is obtained by using grade- 10 data for the secondary level, data from grades 8 and 9 for the middle level, and data from grade 4 for the elementary level.

Figure 2 shows the comparison between U.S. achievement and that of other industrialized nations, aggregated across all subjects and surveys by grade level. Survey results for the elementary and secondary levels are based on reading, mathematics, and science, while the results for the middle level also include civics. Consistent with Hanushek's observation, U.S. students started out doing very well in the elementary grades but declined to average in the middle grades. It also appears that a further though modest decline occurred from the middle to the secondary grades. At the secondary level, $28 \%$ of nations scored significantly above the U.S., $60 \%$ scored at an equivalent level to the U.S., and the remaining $12 \%$ scored significantly below the U.S. Viewed this way, the aggregated results make clear that the U.S. did not perform "poorly" at the secondary level. Instead, the U.S. performed somewhat below average at this level in comparison with other industrialized nations.

Though only about $30 \%$ of industrialized nations scored significantly above the U.S. at either the middle or the secondary grades, the U.S. decline in international competitiveness from the elementary grades is both a puzzle to understand and a problem for the U.S. public education system to address. Whatever the cause, the observed decline in U.S. students' academic competitiveness occurs over a period of years from grades 3 and 4 to grades 7 and 8, as shown by TIMSS 1995..$^{15}$ The decline cannot be explained by a number of important factors, because they are constant across grade levels from elementary to secondary. For example, the organization of the U.S. education system is the same, financial resources for schools are comparable, and the socioeconomic background and academic ability of students do not differ significantly between the elementary and secondary grades. Therefore, the explanation for the U.S. decline in achievement must lie elsewhere. One of two possible explanations is that the quality of instruction declines in U.S. middle and secondary schools relative to that in 
other nations. Another possibility is that students' academic motivation declines in the U.S. relative to that of students in other nations, perhaps as a by-product of an adolescent peer culture that distracts students from academic learning.

\section{U.S. ACHIEVEMENT COMPARED WITH THAT OF THE OTHER G7 NATIONS}

We conclude from the evidence reviewed above that, when compared with students in other industrialized nations, U.S. students do not perform poorly on international achievement surveys. Instead, they perform better than average overall across six international surveys, three grade levels, and four subjects. However, it is also important to consider how the performance of U.S. students compares with that of their peers in the other G7 nations. After all, the list of 22 industrialized nations used for the comparisons above includes a number of minor economic powers such as Iceland, New Zealand, Portugal, and Finland. The G7 nations, on the other hand, are the major economic competitors of the U.S. - the very nations that will cause economic decline if the performance of U.S. students in mathematics and science is as critical to the nation's future economic performance as Colwell has claimed. ${ }^{16}$

The following comparisons between the achievement of U.S. students and that of students in the other G7 nations were based on surveys completed at the middle and secondary grades (i.e., grades 8,9 , and 10) - the grades at which the U.S. was least competitive. First, the performance by subject matter of each of the other six G7 nations was compared with that of the U.S. on the surveys in which both nations participated. These results were then aggregated for the five Western G7 nations other than the U.S. (Western G5) and are shown in Figure 3 in comparison with mean achievement scores for the U.S. and Japan (the only G7 nation from East Asia).

As seen in Figure 3, U.S. achievement is comparable to that of the Western G5 nations in reading, mathematics, and science - and considerably higher in civics. The reading scores of Japanese students are comparable to those of students in the Western G5 nations and the U.S., but they are much higher in mathematics and science. (Japan did not participate in the Civic Education Study.) With respect to academic achievement, the U.S. is quite comparable to other major Western nations, but the Western nations as a whole consistently trail Japan in mathematics and science. ${ }^{17}$ And to the extent that Japan is representative of several highperforming East Asian nations, including Singapore, Korea, Chinese Taipei, and Hong Kong, the perception that the U.S. performs poorly is a phenomenon of the West versus the East, not just the U.S. versus the rest. As with the decline in U.S. achievement scores relative to those of other nations from the elementary grades to the middle grades, the West/East differences in mathematics and science achievement are puzzles to be solved and a potential source of concern for the entire Western world. At least the U.S. performs on a par with other Western G7 nations.

\section{U.S. MINORITY STUDENT ACHIEVEMENT COMPARED WITH THAT OF THE OTHER G7 NATIONS}

Not only does the U.S. have the largest gross domestic product among the G7 nations but it also has by far the

\section{FIGURE 3.}

\section{Scores of U.S. and Other G7 Nations on International Comparisons, by Subject*}

\section{Reading}

Japan

Western G5

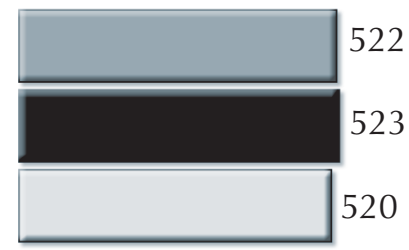

U.S.

2. Mathematics

Japan

Western G5

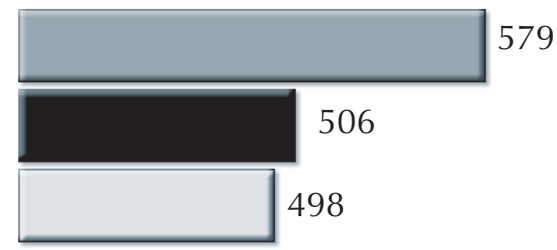

U.S.

\section{Science}

Japan

Western G5

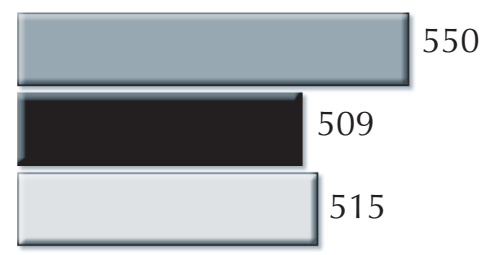

U.S.

4. Civics $\dagger$

Western G5

U.S.

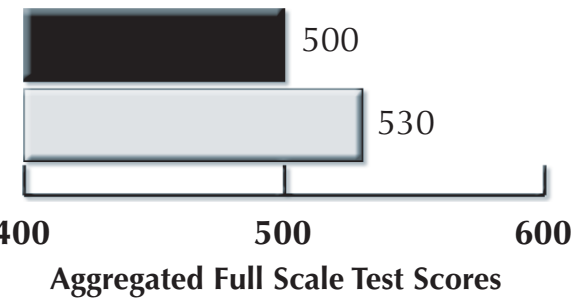

Sources: Five international education surveys sponsored by IEA and one by OECD.

* Results for each subject were aggregated across grades 8, 9, 10.

$\dagger$ Civics scores were converted to a base of 500 for this figure. 
largest and most racially and ethnically diverse population and the largest number of partially autonomous states. Given these differences, how meaningful is it to compare U.S. achievement scores with scores from much smaller and more homogeneous nations, such as England or Japan? During the latter half of the 1990s, the U.S. population was $84 \%$ white (including white Hispanic), whereas the populations of Germany and Italy were nearly $100 \%$ white, and Japan's was nearly $100 \%$ Asian. While the percentage of whites in Canada was similar to that in the U.S., the largest U.S. minority is black (12\%), and the largest in Canada is Asian. ${ }^{18}$ In addition, the U.S. has a large ethnic Hispanic minority. In fall 1996, U.S. public school enrollment was $64 \%$ white, $17 \%$ black, $14 \%$ Hispanic, and $5 \%$ other (Asian, American Indian, etc.). ${ }^{19}$

As is well known, there has long been a substantial gap in the U.S. between the achievement scores of white students and those of black students and between those of white students and those of Hispanic students. Accordingly, we analyzed international survey data to determine the extent to which the performance of U.S. minority students might have affected overall U.S. achievement scores in comparison with those of other G7 nations.

Analyses of U.S. achievement scores for three racial and ethnic groups (white, black, and Hispanic) compared with those of the other G7 nations were limited to surveys completed at the middle and secondary grades (i.e., grades 8, 9, and 10) - the grades at which the U.S. was least competitive. For this purpose, all national mean achievement scores, as well as those for U.S. white, Hispanic, and black students, were converted to percentile rank (PR) scores based on the group of industrialized nations included in each survey. These PR scores were then aggregated for the Western G5 nations and compared with PR scores for the U.S. and Japan.

As seen in Figure 4, achievement scores of white students in the U.S. were consistently higher than those of students in the Western G5 nations, even though these nations were predominantly white. By comparison, the scores of U.S. black and Hispanic students were very low and well below those of the other nations. This is compelling evidence that the low scores of these two groups of minority students were major factors in reducing the comparative standing of the U.S. in international surveys of achievement. If these minority students were to perform at the same level as white students, the U.S. would lead all the other G7 nations (including Japan) in reading and would lead the Western
G5 nations in mathematics and science, though it would still trail Japan in these subjects. ${ }^{20}$

Much has been written about the achievement disparities between groups of students in the U.S., and progress toward closing these gaps is a major objective of the No Child Left Behind (NCLB) Act. Two perspectives on this problem dominate the policy discussion. One side argues that minority students perform poorly because the quality of their schooling is deficient. It is said that there are two sys-

\section{FIGURE 4.}

\section{Percentile Ranks of U.S. Total, U.S. Subgroups, And Other G7 Nations on International Comparisons, by Subject*}

\section{Reading \\ Japan \\ Western G5

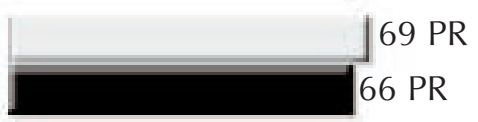 \\ U.S. Total \\ White \\ Hispanic \\ Black

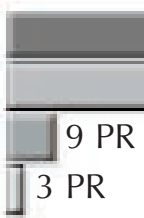 \\ 49 PR}

2. Mathematics

Japan

Western G5
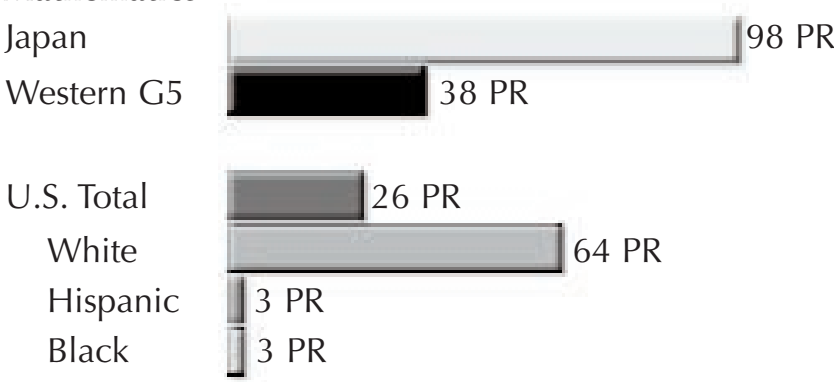

\section{Science}

Japan

Western G5
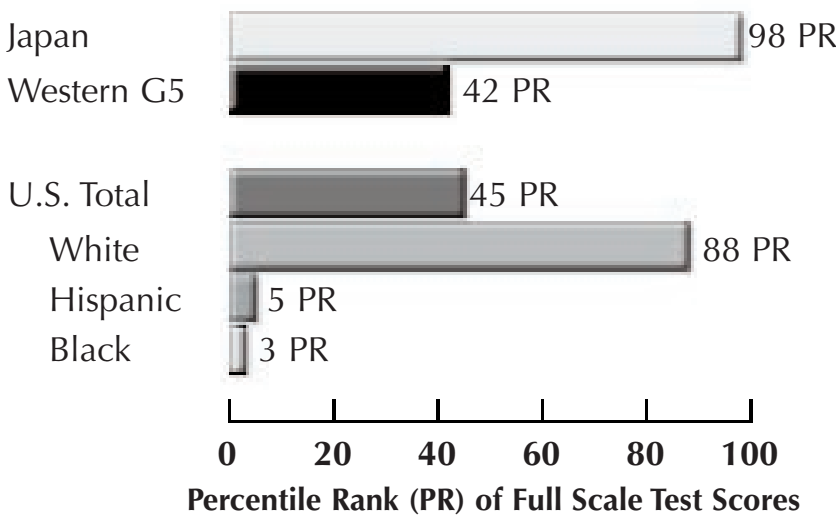

Sources: Four international education surveys sponsored by IEA and one by OECD.

* Results for each subject were aggregated across grades 8, 9, 10. 
tems of public schools in America, a weak and poorly funded system for our black and Hispanic students and another that is academically strong and well funded for the white majority. ${ }^{21}$ The other side argues that the achievement gap is driven by student background variables (e.g., economic disadvantage, limited parental support, discrimination) largely beyond the control of schools. ${ }^{22}$ No doubt there is some validity to both viewpoints. If so, public schools in the U.S. face the problem of providing a type and quality of education that will compensate for the background disadvantages of minority students and make up for deficiencies in their schooling. If these objectives can be achieved, the U.S. may well realize its long-standing national goal of becoming "first in the world" in mathematics and science achievement.

\section{CONCLUSIONS}

Based on our review of the results of six international achievement surveys conducted from 1991 to 2001, we conclude that U.S. students have generally performed above average in comparisons with students in other industrialized nations. Certainly there is variability in performance, with the U.S. scoring above average in reading and civics, average in science, and somewhat below average in mathematics. But even in mathematics at the middle and secondary levels, the U.S. did not perform "poorly." On the positive side, U.S. aggregate scores were above average in all subjects at the elementary levels and in reading and civics across grade levels.

How then can we explain the common perception that the U.S. generally performs poorly in the international achievement horse race? There are several plausible reasons for this, all of which might be partly correct. First, many consumers of comparative achievement statistics simply are not aware of the results of the full array of surveys that have been conducted in recent years. This may be due, in part, to the selective reporting of bad news and neglect of good news common to the press. ${ }^{23}$ We hope the results reported here will provide more comprehensive factual information on which anyone can base generally valid conclusions about the achievement of U.S. students in international comparisons.

Second, it may be that others are aware of the achievement results of the full array of surveys but simply view average results as poor because they expect the U.S. to be "first in the world" academically, as it is in economic strength and military power. In this view, anything less than first place is regarded as a poor performance. Some actually might have taken seriously the political hype represented in the national goal adopted in 1990 by state governors and President George H. W. Bush that "U.S. students will be first in the world in science and mathematics achievement" by the year 2000. ${ }^{24}$

This aspiration, however, is unreasonable. The U.S. is not "first in the industrialized world" in minimizing the percentage of its population living in poverty or in minimizing its infant mortality rate..$^{25}$ So why should anyone expect the U.S. to be first in the world in educational achievement? There is, after all, abundant evidence that these types of social indicators are strongly associated with educational achievement.

Third, some observers might pick and choose from among existing surveys only the results that support their belief that American public education is inadequate, disregarding evidence to the contrary. This group may include both well-meaning reformers of public education and well-meaning conservatives who view public education as an untenable public monopoly that must be privatized as much and as quickly as possible. The biased selection of evidence is not a surprising or uncommon strategy for advocates of a particular cause and may have strong policy and political impact. ${ }^{26}$

Is it reasonable to expect that in the next few decades U.S. student achievement in mathematics and science will improve to the point where assessment scores are substantially and consistently well above average? Regardless of current efforts to improve public school outcomes, this seems most unlikely. At best, we can hope for incremental improvement such as that which seems to have occurred in recent years based on our results in comparison with international surveys administered before 1991.27

A major impediment to higher average achievement scores in the U.S. is the performance of its black and Hispanic students. The achievement gap goes back decades and is not closing rapidly (if at all). Moreover, demographic trends exacerbate the impact of the achievement gap on U.S. mean achievement scores. In 1991, the population of public school students was $70 \%$ white and $26 \%$ black and Hispanic. By the year 2000, black and Hispanic students represented about $34 \%$ of the student population, a stunning growth of $8 \%$ during a 10-year period (or growth of nearly $1 \%$ per year). ${ }^{28}$ If the achievement gap remains constant, we can predict that U.S. mean scores will decline as the minority population increases as a percentage of the total.

This article should not be read as a defense of the status quo or an apology for inadequacies in U.S. public education. There is always room for improvement. In fact, all nations seem to be displeased with their education systems and levels of attainment. In the mid-1990s, the OECD spon- 
sored an international study of innovative methods in mathematics and science instruction in 23 nations. ${ }^{29}$ One of the interesting findings was that none of these nations, including some that performed well above average in the international horse race, was satisfied with their mathematics and science teaching and learning. All were striving to improve, just as the U.S. has been - especially since the release of A Nation at Risk in 1983.

In recent years, the U.S. has not performed "poorly" in international comparisons in a statistical sense. Consequently, an allegation of poor performance should not be used to tarnish the constructive work of the majority of public educators and the genuine attainments of U.S. students. Nonetheless, the public and policy makers should continue to expect and demand improvements in instruction from educators and the educational system and improvements in learning from students - especially in those subjects and grade levels where student achievement plainly lags. Likewise, the public and policy makers should give credit where due and recognize genuine achievements in providing effective instruction by educators and in effective learning by students.

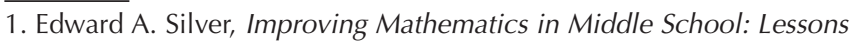
from TIMSS and Related Research (Washington, D.C.: Office of Educational Research and Improvement, U.S. Department of Education, 1998), p. 1.

2. Effective Mathematics Education Research Grants: Request for Application Number NCER-03-05 (Washington, D.C.: Institute of Education Sciences, 15 January 2003).

3. Rita R. Colwell, "National Science Foundation Director's Statement," in Patrick Gonzales et al., eds., Pursuing Excellence: Comparisons of International Eighth-Grade Mathematics and Science Achievement from a U.S. Perspective, 1995 and 1999 (Washington, D.C.: National Center for Education Statistics, U.S. Department of Education, 2000) pp. vii-viii.

4. Albert E. Beaton et al., Mathematics Achievement in the Middle School Years: IEA's Third International Mathematics and Science Study (Boston: Center for the Study of Testing, Evaluation, and Educational Policy, Boston College, November 1996).

5. National Center for Education Statistics, Reading Literacy in the United States: Findings from the IEA Reading Literacy Study (Washington, D.C.: U.S. Department of Education, 1996).

6. A Nation at Risk: The Imperative for Educational Reform (Washington, D.C.: National Commission on Excellence in Education, 1983), p. 9.

7. Because most critiques of U.S. student performance on international assessments emphasize the comparison between their performance and that of students in other industrialized nations, we emphasize such comparisons in this article.

8. The six surveys analyzed included Reading Literacy Study (RLS 1991); Progress in International Reading Literacy Study (PIRLS 2001); Third International Mathematics and Science Study (TIMSS 1995); Third International Mathematics and Science Study - Repeat (TIMSS 1999); Programme for International Student Assessment (PISA 2000), a survey of reading, mathematics, and science; and Civic Education Study (CES 1999).

9. These 22 nations were classified as industrialized by the International Monetary Fund Statistics Department in 2002 and as "High Income OECD Members" by the World Bank in 2003 and included Australia, Austria, Belgium, Canada, Denmark, England, Finland, France, Germany, Greece, Iceland, Ireland, Italy, Japan, the Netherlands, New Zealand, Norway, Portugal, Spain, Sweden, Switzerland, and the U.S.

10. For detailed tables of results for each international survey and for an explanation of our methods of data aggregation across surveys, see Erling E. Boe and Sujie Shin, Is the United States Winning or Losing the International Horse Race in Academic Achievement? Neither — It Is Running with Other Western G7 Nations (Philadelphia: Center for Research and Evaluation in Social Policy, University of Pennsylvania, Research Report No. 2004TIMSS1, 2004).

11. James S. Braswell et al., The Nation's Report Card: Mathematics 2000 (Washington, D.C.: National Center for Education Statistics, U.S. Department of Education, 2001).

12. Eric A. Hanushek, "The Seeds of Growth," Education Next, Fall 2002, pp. 10-17.

13. Boe and Shin, op. cit.

14. Knowledge and Skills for Life: First Results from PISA 2000 (Paris: Organisation for Economic Co-operation and Development, 2001).

15. Albert E. Beaton et al., Science Achievement in the Middle School Years: IEA's Third International Mathematics and Science Study (Boston: Center for the Study of Testing, Evaluation, and Educational Policy, Boston College, 1996); and Beaton et al., Mathematics Achievement in the Middle School Years.

16. Colwell, op. cit.

17. The average performance of Japanese students on mathematics and science assessments can be compared with that of students from other G7 nations on TIMSS 1995, TIMSS 1999, and PISA. At the eighth- and 10th-grade levels, Japanese students scored significantly higher than did students from all other G7 nations, except for students from England, who scored at the same level as Japanese students in science on two of these surveys.

18. Central Intelligence Agency, The World Factbook, 2000 (Washington, D.C.: Brassey's Inc., 2000).

19. National Center for Education Statistics, Digest of Education Statistics: 1998 (Washington D.C.: U.S. Department of Education, 1999).

20. Trevor Williams and Leslie Jocelyn, "The Distribution of Student Achievement," in Mathematics and Science in the Eighth Grade: Findings from the Third International Mathematics and Science Study (Washington, D.C.: National Center for Education Statistics, U.S. Department of Education, 2000), pp. 49-84. Williams and Jocelyn reported that the TIMSS 1995 science scores of U.S. white students and Japanese students in the eighth grade were not significantly different.

21. Arthur Levine, "My Old Neighborhood," president's report, in Teachers College Annual Report (New York: Teachers College, Columbia University, August 2003), available at www.tc.columbia.edu/news/article. htm?id=4459; and Gerald W. Bracey, "International Comparisons: An Excuse to Avoid Meaningful Educational Reform," Education Week, 23 January 2002, pp. 30, 32.

22. Christopher Jencks et al., Inequality: A Reassessment of the Effect of Family and Schooling in America (New York: Basic Books, 1972); and Andrew C. Porter, "Prospects for School Reform and Closing the Achievement Gap," paper presented at the invitational conference of the Educational Testing Service, "Measurement and Research Issues in a New Accountability Era," New York, 3-4 October 2003.

23. Gerald W. Bracey, "The Media's Myth of School Failure," Educational Leadership, vol. 52, 1994, pp. 80-83.

24. The National Education Goals Report: Building a Nation of Learners (Washington, D.C.: National Education Goals Panel, 1991).

25. Central Intelligence Agency, The World Factbook, 2004 (Washington, D.C.: Brassey's Inc., 2004).

26. Carol H. Weiss, "The Many Meanings of Research Utilization," Public Administration Review, September/October 1979, pp. 426-31. Weiss referred to this practice as the political model of research utilization.

27. Richard M. Jaeger, "Evaluating Policy Inferences Drawn from International Comparisons of Students' Achievement Test Performances," Studies in Educational Evaluation, vol. 20, no. 1, 1994, pp. 23-39.

28. National Center for Education Statistics, Digest of Education Statistics: 1993 (Washington D.C.: U.S. Department of Education, 1993); and National Center for Education Statistics, Digest of Education Statistics: 2001 (Washington D.C.: U.S. Department of Education, 2002).

29. Paul Black and J. Myron Atkin, Changing the Subject: Innovations in Science, Mathematics, and Technology Education (London: Routledge, 1996). 